EXTENDED REPORT

\title{
Burden and cost of illness in patients with juvenile idiopathic arthritis
}

\author{
K Minden, M Niewerth, J Listing, T Biedermann, M Schöntube, A Zink
}

Ann Rheum Dis 2004;63:836-842. doi: 10.1136/ard.2003.008516

See end of article for authors' affiliations

Correspondence to:

Correspondence to:
Dr. K Minden, Deutsches Rheuma-Forschungszentrum Berlin, Schumannstr. 21/22, 10117 Berlin, Germany; minden@drfz.de

Accepted 6 August 2003

\begin{abstract}
Objective: To estimate the cost of illness in an incidence based cohort of patients with juvenile idiopathic arthritis.

Methods: Direct costs (healthcare and non-healthcare costs) and indirect costs (productivity loss due to sick leave and work disability) were measured in $215 \mathrm{JIA}$ patients, assessed on an average of 17 years after disease onset. Assessment included a clinical evaluation, a structured interview, and two self completion questionnaires. Annual direct costs were estimated based on the reported use of healthcare services and resources, using average unit prices. Indirect costs were estimated from the number of work days missedthat is, using the human capital approach.

Results: The mean total cost of late JIA was estimated to be $€ 3500$ per patient and year, of which the direct cost contributed more than half. Patients with still active disease (55\%) incurred the major share (90\%) of the cost. They had a mean total cost of $€ 5700$ per patient year, with those under rheumatological care incurring a cost of $€ 9300$. Having a certain JIA subgroup, functional disability, or receipt of specialised care independently contributed to the total cost in active JIA. Highest mean total costs were found in active seropositive polyarthritis $(€ 17000)$ and extended oligoarthritis (€11 000), while the lowest were found in active enthesitis related arthritis $(€ 1500)$ and persistent oligoarthritis $(€ 2700)$.

Conclusions: Estimated 12 month costs in late JIA are considerable, differing among the various JIA subgroups. Treatment strategies in JIA should be analysed for their cost effectiveness in the long term.
\end{abstract}

imited resources and rapid increments in healthcare expenditure in all countries have led to an increased -interest in the economic impact of various diseases. Musculoskeletal disorders have gained special attention, with numerous studies showing their tremendous economic burden. ${ }^{1-6}$ Although literature on the cost of illness in rheumatic diseases has burgeoned in recent years, there has been very little research into cost of juvenile idiopathic arthritis (JIA). ${ }^{78}$

JIA represents a heterogeneous group of chronic inflammatory arthritides in children, and is very variable in its presentation and course. While many patients experience remission, as many as $50 \%$ enter adulthood with active disease and functional limitation. ${ }^{9} 10$ Recent studies have shown that adult JIA patients have to cope with impairments of body functions and structures, limitations to their activity, and restricted participation in society ${ }^{9-14}$ This may result in a considerable impact on the individual, their family and friends, and society.

This study aimed to assess the socioeconomic impact of JIA, and to provide information about the magnitude of JIA associated costs relating to the different JIA subgroups, disease activity, functional limitation, and types of healthcare provision.

\section{METHODS}

\section{Study design}

This was an incidence based, retrospective study conducted from a societal and patient's perspective, estimating 12 month costs associated with late JIA.

\section{Study population}

The data for the present cost analysis were derived from a 17 year follow up study. ${ }^{9}$ The whole cohort comprised 215 JIA patients, (83\% of the original cohort), who were assessed at the 2nd Children's Hospital between 1998 and 2000. All patients met the modified International League of Associations for Rheumatology criteria for JIA $^{15}$ at disease onset and had been referred to the Children's Hospital at Berlin-Buch between 1978 and 1988 (for greater detail, see Minden $e t a l^{9}$ ).

\section{Outcome definition}

Assessment included a clinical examination and a global physician's assessment of functional status (numeric rating scale from 0 to 10 on the Numeric Rating Scale-11 (NRS-11), and Steinbrocker functional status ${ }^{16}$ ) and disease activity (NRS-11, remission according to defined criteria ${ }^{17}$ ). For this study, a patient was considered to be in remission if he/she had had no active uveitis or inflammatory back pain for at least 2 months and fulfilled five or more of the following criteria: morning stiffness not exceeding 15 minutes, no fatigue, no joint pain, no joint tenderness, no swelling in joints or tendon sheaths, and/or an erythrocyte sedimentation rate $(\mathrm{ESR})<20 \mathrm{~mm} /$ hour. In addition, patients rated their pain, functional status, general health, and disease activity on NRS-11. Self completion questionnaires containing standardised instruments, such as German versions of the Health Assessment Questionnaire $\left(\mathrm{HAQ}^{18}\right)$, the Rheumatoid Arthritis Quality of Life Questionnaire $\left(\mathrm{RAQol}^{19}\right)$, and the Center for Epidemiologic Studies Depression Scale $\left(\mathrm{CES}-\mathrm{D}^{20}\right)$, were additionally employed. The patients also assessed their burden of illness concerning their physical, psychological, professional, financial, and family situation on a 4 point

Abbreviations: CES-D, Center for Epidemiologic Studies Depression Scale; DMARDs, disease modifying anti-rheumatic drugs; FC, friction cost; $H A Q$, Health Assessment Questionnaire; JIA, juvenile idiopathic arthritis; NRS-1 1, Numeric Rating Scale-11; NSAIDs, non-steroidal antirheumatic drugs; RA, rheumatoid arthritis; RAQol, the Rheumatoid Arthritis Quality of Life Questionnaire 
Likert scale ranging from "not at all" to "very much" and reported on their need for help with daily routines.

\section{Resource use data}

Resource use data were obtained from the study participants by use of self completion questionnaires and a structured interview. Data on the patient's functional capacity, quality of life, depressive symptoms, income, vocational status, and out of pocket expenses were obtained by questionnaire, while information on the current state of signs and symptoms, current treatment, number and type of comorbidities, and use of healthcare services and resources over the preceding 3 months was collected by interview. Subsequently, a full review of the patient's clinical notes was performed to verify the interview/questionnaire data, including the medical records from the Children's Hospital, which were available for all patients, and those available for approximately half the patients still receiving medical care. No relevant differences between the information obtained from the patients and that given in the records were noted.

Table 1 summarises the estimates of unit prices used in this article. The average price of a rheumatologist visit estimated by Merkesdal et al. ${ }^{21}$ was used as the unit price for rheumatology service use. This tariff had been estimated by those authors by means of a survey amongst rheumatologists, providing an average physician charge inclusive of routine laboratory tests and imaging. Unit prices for non-rheumatologist visits were valued according to data from the Federal Association of Panel Doctors, based on the German Act for Physician Charges. ${ }^{22}$ Standardised reimbursement rates by the health insurance companies for specific services were used as the unit prices for non-physician service use (such as physiotherapy and occupational therapy). ${ }^{23}$ The Red List ${ }^{\circledR 24}$ was the source for unit prices of specific drugs, from which the annual cost was estimated for the reported or a standard drug dose. An average price was used when only the substance was known. To estimate the cost of inpatient care for JIA, the daily generic hospital cost in Germany according to the federal statistical state office ${ }^{26}$ was applied. A standardised unit price based on the average expenditure by pension insurance companies for a medical service in $1999^{28}$ was applied for the use of non-acute hospital facilities. For all analyses, 1999 unit prices were used.

Non-healthcare costs expended by the patients covered 3 months and included disease related expenditures such as transportation, alterations to the home, cash adjustments to prescribed therapy, non-prescribed and alternative therapy, use of private and community services, and special equipment. All costs were converted into euros, applying 1.95583 German marks to 1 euro.

\section{Cost estimation}

To estimate the total annual outpatient cost of JIA, the number of each service type used because of JIA within the preceding 3 months was multiplied by 4 , as was by the unit price for that service, and the two subsequently added together. For the estimation of hospitalisation cost, all acute hospital admissions with and without surgery related to JIA were considered. The cumulative number of days in hospital within the preceding 12 months was multiplied by the daily generic hospital cost. Additional charges for specific surgery, such as joint replacement, were taken into account. To calculate the rehabilitation cost, the average price per measure was applied, then inpatient and outpatient costs were added to calculate the total cost of direct medical care. Patient expenditures reported for the preceding 3 months were multiplied by 4 to compute the annual non-healthcare cost. Both healthcare and non-healthcare costs were then added to calculate the direct JIA cost.

The indirect costs of JIA were evaluated for the whole JIA group and for the active population $(\mathrm{n}=105)$, which refers to those aged 16 years or over who were working or willing to work. Consequently, younger patients, students, and housewives were excluded from this group. The productivity costs were calculated by means of the human capital approach, taking into account all costs to society that arose from lost productivity caused by sick leave and work disability (complete cessation of employment and entitlement to a social security pension). The cumulative number of work days lost over the preceding 12 months was calculated for each patient individually. Population data of the year $1999^{29}$ were used for the valuation of the loss of productivity. An estimate of the loss of productivity was obtained by multiplying the number of work days lost per year by the gross annual income of all gainfully employed workers (€1.053 billion), divided by the total number of labour force participants ( 32.497 million) and by 365 days. Thus, the cost of lost productivity amounted to approximately €89/person/ day.

Table 1 Sources of unit costs and resource use (cumulative number of used resources per year, proportion of patients having used that resource)

\begin{tabular}{|c|c|c|c|c|}
\hline \multirow[b]{2}{*}{ Expenditure costs assessed } & \multicolumn{2}{|l|}{ Resource use } & \multirow[b]{2}{*}{$\begin{array}{l}\text { Applied unit prices in } € \\
\text { (superscripts are references) }\end{array}$} & \multirow[b]{2}{*}{ Utilisation reference } \\
\hline & Annual number & $\begin{array}{l}\text { Number of } \\
\text { patients (\%) }\end{array}$ & & \\
\hline \multicolumn{5}{|l|}{ Direct costs } \\
\hline \multicolumn{5}{|l|}{$\begin{array}{l}\text { Healthcare costs } \\
\text { Outpatient costs }\end{array}$} \\
\hline JIA-related rheumatology service use & 517 & $82(38)$ & $49^{21}$ & Interview, records \\
\hline Other JIA-related physician service use & 885 & $97(45)$ & $30^{22}$ & Interview \\
\hline Non-physician service use & 1500 & $42(19)$ & Standardised rates/unit ${ }^{23}$ & Interview \\
\hline Surgery & 1 & $1(0.5)$ & Average charge $^{22}$ & Interview \\
\hline Medication & NA & $83(39)$ & Average medication price ${ }^{24}$ & Interview, records \\
\hline Devices and aids & NA & $67(31)$ & Average price $^{25}$ & Interview, questionnaire \\
\hline \multicolumn{5}{|l|}{ Inpatient costs } \\
\hline Acute hospital facilities & 606 days & $24(11)$ & $300 /$ day $^{26}$ & Interview, records \\
\hline Surgery & 2 & $2(1)$ & Case based lump sum ${ }^{27}$ & Interview, records \\
\hline Non-acute hospital facilities (rehabilitation) & NA & $6(3)$ & $4511 /$ stay $^{28}$ & Interview \\
\hline Non-healthcare costs & & & & \\
\hline Patient expenditures ( 3 months) & NA & $71(33)$ & & Questionnaire \\
\hline \multicolumn{5}{|l|}{ Indirect costs } \\
\hline Loss of productivity & 913 days & $23(11)$ & $89 /$ day $^{29}$ & Questionnaire, interview \\
\hline
\end{tabular}




\section{Statistical analysis}

Statistical analyses were performed using an SPSS database (version 10.0). The main descriptive statistics presented are the arithmetic mean, standard deviation (SD), median, and interquartile range (IQR). Bootstrap estimates were used to calculate the $95 \%$ confidence intervals (CI) by means of Gauss Mathematical and Statistical System software. ${ }^{30}$ Kruskal-Wallis test and Mann-Whitney U test were used for statistical comparisons. Spearman's rank correlation was applied to study the correlation between direct and indirect cost. To evaluate the contribution of various disease variables to the costs in the whole cohort and in active JIA, respectively, two analyses were performed: a logistic regression analysis with backward elimination and cumulative logit models for ordinal responses in which the JIA groups were summed up to two groups with clearly different costs. The latter analysis contrasting four groups with different costs (€0, €1-500, €501-5000, and >€5000) considered the following variables: JIA subgroup (persistent oligoarthritis or enthesitis related arthritis; systemic arthritis, extended oligoarthritis, or seropositive polyarthritis), HAQ score (0, $0.13-0.74$, and $\geqslant 0.75)$, CES-D score $(0-10,11-15$, and $\geqslant 16)$, and utilisation of specialised care (no or yes). A p value $<0.05$ was considered statistically significant.

\section{Sensitivity analysis}

Due to the wide range in reimbursement rates for outpatient visits and inpatient stays across Germany, applied generic unit costs for outpatient visits and inpatient stays were uncertain parameters. In 1999, rates for outpatient visits varied by $35 \%$ depending on federal state, health insurance, and specialist, ${ }^{22}$ while cost for inpatient care varied by $55 \%$ among the different hospitals and federal states. ${ }^{26}$ In order to investigate the sensitivity of the cost estimated, the applied prices for the respective parameters were thus varied by the aforementioned percentages. In addition, as evaluation of the indirect costs according to the human capital approach leads to an overestimation of productivity costs in economic systems with underemployment, the friction cost method (FC) was also used to calculate productivity costs. This method limits the time of productivity loss to that period until replacement of the worker has taken place, assumed to equal to an average vacation period. ${ }^{31}$ Therefore, in this analysis, costs due to productivity loss by the patients having been retired or on sick leave for more than 6 weeks were not taken into account to calculate indirect FC.

\section{RESULTS}

Out of 260 JIA patients referred to the 2nd Children's Hospital at Berlin-Buch between 1978 and 1988, 215 (83\%) could be assessed. From table 2, it can be observed that more than half were female, mean age was 23 years, and mean disease duration was 17 years.

\section{Outcome}

At follow up, 45\% of the JIA patients were in remission according to the defined criteria, although slightly more of the patients $(48 \%)$ considered their disease as being inactive (NRS-11 $=0$ ). As regards general health, 69\% felt somewhat limited (NRS-11>0), with $25 \%$ stating moderate to severe restrictions (NRS-11 $\geqslant 4$ ). This was predominantly due to their rheumatic illness, as comorbidities were infrequent; they included atopic disorders in $20 \%$, nephrolithiasis in $5 \%$, osteoporosis in 3\%, and psychiatric disorders in 3\% of the patients. Overall, impairments in functioning (HAQ score $>0$ ) and quality of life (RAQol score $>0$ ) were reported by $39 \%$ and $60 \%$, respectively. As assessed by the HAQ, $9 \%$ of patients needed assistance with activities of daily living, and when asked in general, $24 \%$ stated the need for help in order

\begin{tabular}{lc}
\hline Table 2 Characteristics of study participants \\
\hline Patients' characteristics \\
\hline Number of patients \\
Female (\%) \\
JIA subgroups, $n$ (\%) \\
Systemic arthritis \\
Oligoarthritis & 215 \\
Seronegative polyarthritis & $30(14)$ \\
Seropositive polyarthrtis & $85(40)$ \\
Psoriatic arthritis & $27(13)$ \\
Enthesitis related arthritis & $3(1)$ \\
Other arthritis & $3(1)$ \\
Mean age, years (SD) & $33(15)$ \\
Mean disease duration, years (SD) & $34(16)$ \\
Steinbrocker functional class, $n$ (\%) & $23(5.3)$ \\
I & $17(4.0)$ \\
II & $118(55)$ \\
III & $75(35)$ \\
IV & $21(10)$ \\
Patient status, $n(\%)$ & $1(0)$ \\
Students/trainees & $94(44)$ \\
Employees & $85(40)$ \\
On maternity leave & $13(6)$ \\
Retired & $8(4)$ \\
\hline & \\
\hline
\end{tabular}

to be able to engage in their daily routines at all. That help was provided by a paid social worker in only $2 \%$ of the cases.

Of those not having attained remission, $90 \%$ and $80 \%$ of patients respectively reported impairments of global health (NRS-11 $>0$ ) and quality of life (RAQol $>0$ ). Functional limitations were stated by $63 \%$ (HAQ score $>0$ ) and $51 \%$ (NRS-11 >0), respectively. Joint pain within the previous week was reported by $78 \%$, and restrictions in motion of at least one joint were observed in $80 \%$. Almost $90 \%$ of the patients with active disease considered themselves to be physically burdened and 56\% felt emotionally burdened by their illness. Moreover, $64 \%$ claimed to be somewhat burdened by the illness in terms of their professional goals or at the workplace. However, only $50 \%$ of them had been seen by a rheumatologist at least once within the preceding 12 months. Of the patients not in remission, $40 \%$ were receiving disease modifying anti-rheumatic drugs (DMARDs) and $37 \%$ non-steroidal anti-rheumatic drugs (NSAIDs) at follow up. Physiotherapy had been prescribed to only $28 \%$. Overall, one third of the patients with an active disease were rated as being insufficiently provided with specialised care by the assessing physician, taking into account complaints stated by the patients, and results of the laboratory and clinical assessments. Patients under rheumatological care were the more severe cases; more than half $(56 \%)$ had systemic arthritis, extended oligoarthritis, or polyarthritis, whereas these subgroups amounted to less than one third in those cases treated only by general practitioners. Furthermore, these patients had a significantly higher mean disease activity (3.9 $v 2.3$ on NRS-11, p=0,001) and functional limitation ( $1.9 v 1.0$ on NRS-11, p = 0.023) than those treated by general practitioners.

\section{Total cost of illness}

The number of resources used by the JIA patients and the proportion of patients having used these resources over the preceding 12 months form the basis of the cost estimation given in table 1 . The resultant total mean cost was estimated to be €3471 per JIA patient and year (95\% CI €2257 to €4685). Of the total cost, 55\% was incurred by the healthcare service in the form of visits to health professionals, inpatient stays, and medications, and by the patient in the form of nonhealthcare cost. The remaining $45 \%$ of the total cost was indirect cost due to loss of productivity. Only a small 
proportion of the patients incurred high cost; $12 \%(n=26)$ were responsible for $80 \%$ of all costs, while $30 \%$ caused no cost at all.

When the various JIA subgroups were compared, it was seen that mean total cost diverged significantly among them $(p<0.001)$. Patients with seropositive polyarthritis and extended oligoarthritis incurred the highest total mean cost, while patients with persistent oligoarthritis incurred the lowest mean cost. The mean healthcare, non-healthcare, and indirect costs related to subgroup are summarised in table 3.

As would be expected, persistent disease activity, functional disability, and restricted quality of life were associated with significantly higher cost $(p<0.001)$, as shown in table 4 . Furthermore, patients with an active disease who received specialised care incurred a higher cost than those not receiving such care (mean €9292 $v € 2069$ ), which was due not only to a higher direct cost ( $€ 4994 v € 1269)$, but also to a higher indirect mean cost ( $€ 4298 v € 800)$.

In multivariate analysis contrasting patients with no $v$ any cost, absence of remission $(p=0.041)$ and utilisation of specialised care $(p<0.001)$ were determinants of the total cost. Altogether, the patients without remission incurred 90\% of all costs. In the multivariate cumulative logit analysis it was found that presence of functional limitation, JIA subgroup, and utilisation of rheumatological care significantly contributed to the total cost in active JIA. Having a HAQ score of $0.13-0.74$ or a score of $\geqslant 0.75$ significantly increased the risk of incurring higher cost (OR 4.0; 95\% CI 1.4 to $11.6 ; \mathrm{p}=0.005$ and OR $8.5 ; 95 \%$ CI 1.9 to $37.7 ; \mathrm{p}=0.005$, respectively). Furthermore, patients with systemic arthritis, extended oligoarthritis, or seropositive polyarthritis had an increased risk of incurring higher cost (OR 3.5; 95\% CI 1.3 to 9.5; $\mathrm{p}=0.014)$, as had those under rheumatological care (OR 10.5; $95 \%$ CI 3.6 to $33.3 ; \mathrm{p}<0.001)$. Generally, direct and indirect costs were found to be positively associated (Spearman's rank correlation coefficient $r_{S}=0.4 ; p<0.001$ ).

\section{Direct cost}

Healthcare cost accounted for the major part of the direct cost (96\%), while non-healthcare cost was almost negligible. Despite there being only $26(12 \%)$ reported inpatient stays (acute and non-acute), these accounted for $53 \%$ of the direct and $55 \%$ of the total healthcare cost incurred by the entire cohort. Outpatient care took $43 \%$ of direct cost. Visits by health professionals accounted for 25\% (5\% rheumatology service use, $6 \%$ other JIA-related physician service use, 14\% non-physician service use), devices and aids for 3\%, and medications for $14 \%$ of direct care cost. Drugs cost was split as follows: $48 \%$ due to DMARDs, $17 \%$ to NSAIDs, $5 \%$ to osteoporosis treatment/prophylaxis, and $7 \%$ to gastroprotective agents. Only $26 \%$ of all patients were taking DMARDs
Table 4 Annual JIA costs $(€)$ by selected parameters

\begin{tabular}{|c|c|c|c|}
\hline & $\mathrm{n}$ & Mean (SD) & Median (IQR) \\
\hline \multicolumn{4}{|l|}{ Remission } \\
\hline Yes & 97 & 782 (3809) & $51(0-254)$ \\
\hline No & 118 & 5681 (11243) & $1170(70-4916)$ \\
\hline \multicolumn{4}{|c|}{ Disease activity* } \\
\hline 0 & 100 & 430 (1337) & $13(0-240)$ \\
\hline $1-3$ & 68 & 3772 (7888) & $738(64-3280)$ \\
\hline $4-6$ & 27 & $5428(8486)$ & $1173(792-8085)$ \\
\hline $7-10$ & 18 & 15101 (20495) & $2714(1227-32899)$ \\
\hline \multicolumn{4}{|c|}{ HAQ score $†$} \\
\hline 0 & 130 & 917 (3273) & $51(0-303)$ \\
\hline $0.1-0.74$ & 57 & $4558(8435)$ & $1370(258-5007)$ \\
\hline$\geqslant 0.75$ & 26 & 13034 (18076) & $3653(1150-23238)$ \\
\hline \multicolumn{4}{|c|}{ RAQoL score } \\
\hline 0 & 84 & 424 (1987) & $28(0-128)$ \\
\hline $1-4$ & 71 & 2568 (5447) & $760(26-2872)$ \\
\hline $5-14$ & 48 & 8743 (15284) & $1387(234-9445)$ \\
\hline$\geqslant 15$ & 5 & 11730 (13669) & $6931(2072-23789)$ \\
\hline \multicolumn{4}{|c|}{ CES-D score§ } \\
\hline $0-10$ & 172 & 2785 (7344) & $141(0-1441)$ \\
\hline $11-15$ & 20 & 8088 (17432) & $939(65-7932)$ \\
\hline$\geqslant 16$ & 16 & $4670(9138)$ & $741(42-5805)$ \\
\hline
\end{tabular}

and $21 \%$ NSAIDs at follow up. Patients with active disease incurred direct costs of approximately $€ 3000$ per year, whereas those with remission incurred only $€ 400$ (table 5). While the proportion of the non-healthcare cost was similar in both patient groups, other components contributed in different extents to the direct costs, as shown in fig 1.

The total annual mean non-healthcare cost incurred by the patients was rather low (€77), contributing to $4 \%$ of the direct cost. The largest proportion was due to cash adjustments to prescribed inpatient and outpatient treatments $(€ 46)$, followed by expenditure for non-prescribed/alternative therapy (€20), and transportation (€11).

\section{Indirect cost}

While indirect cost amounted to $45 \%$ of the total cost in the whole cohort, it made up $68 \%$ of the total cost in the active population. Cost due to sick leave was $16 \%$ of the indirect costs in the active population. Within the preceding 12 months, $16 \%$ of the active population $(28 \%$ of those with active disease) had been on sick leave, with a mean number of 34 days (range 2-120) of sick leave because of JIA per patient year. Patients with a part time job incurred significantly higher indirect and total costs than those employed full time (€1791 $v € 199$ and $€ 5057 v € 898$, respectively; $\mathrm{p}=0.001)$. With regard to the active population, mean indirect costs were highest in patients with seropositive

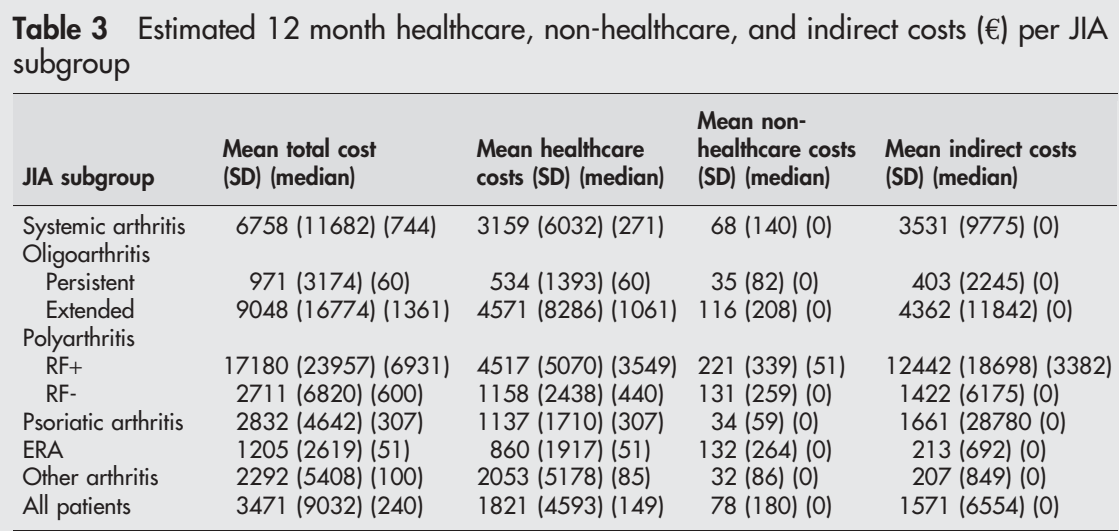

$\mathrm{RF}+$, rheumatic factor seropositive; $\mathrm{RF}-$, rheumatic factor seronegative; ERA, enthesitis related arthritis 


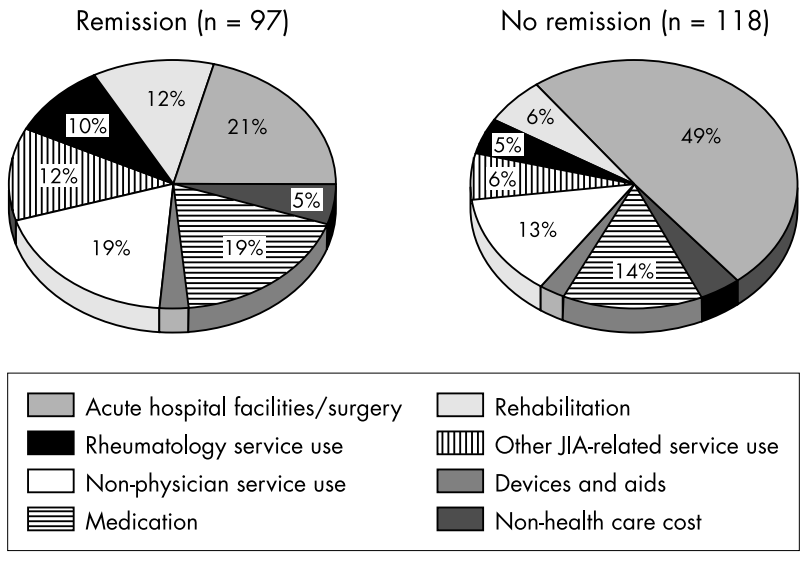

Figure 1 Direct costs incurred by patients not in remission $v$ those having attained remission.

polyarthritis and extended oligoarthritis, where they contributed to $73 \%$ and $74 \%$ to the total cost. In contrast, the lowest indirect costs were estimated for patients with persistent oligoarthritis and enthesitis related arthritis (table 6).

\section{Sensitivity analysis}

The variation of the uncertain variables as reimbursement rates for outpatient (rheumatologist and non-rheumatologist) visits and inpatient stays by $\pm 35 \%$ and $\pm 55 \%$ resulted in a maximum change in healthcare cost of $30 \%$ and in total cost of $16 \%$. In fact, the lower extreme for the mean healthcare cost (that is, reducing outpatient cost by 35\% and inpatient cost by $55 \%$ ) was $€ 1278$, and the upper extreme (that is increasing outpatient cost by $35 \%$ and inpatient cost by $55 \%$ ) was $€ 2365$. Estimated lower and upper extremes for the mean total 12-month cost amounted to €2927 and €4014, respectively.

Applying the FC the indirect cost in the active population is $€ 269$, which is approximately one tenth of that estimated by means of the human capital method. The indirect FC accounts for $25 \%$ of the total cost-that is, €1087 or one third of that estimated by the human capital method.

\section{DISCUSSION}

Economic questions are now central to the practice of medicine in general and of rheumatology in particular. Recent data have shown the major economic impact of some musculoskeletal diseases on patients' daily life and on society. ${ }^{32-35}$ However, little information is available concerning the cost of JIA, the most common chronic inflammatory rheumatic disease in children.

To our knowledge, this is the first retrospective incidence based study providing descriptive data on the pattern of resource used by patients with late JIA. The study has shown that after a mean disease duration of 17 years, $55 \%$ of the JIA patients still had an active disease and $40 \%$ received specialised healthcare. Absence of remission and utilisation of rheumatological care were the main contributors to the total cost, up to approximately $€ 3500$ per patient year in this JIA cohort. This cost appears rather low, but it has to be borne in mind that: (a) this study was incidence based, and therefore included patients (45\%) who had attained remission; (b) approximately one third of the patients with active disease were insufficiently provided with specialised care, and therefore incurred a lower healthcare cost; and (c) more than $40 \%$ were students for whom days absent from college or university due to JIA were not taken into account when calculating the productivity loss. However, patients with active disease incurred an annual cost of approximately $€ 5700$, with those under specialised care incurring €9000. This is similar to total costs estimated for patients with chronic arthritides acquired in adulthood, such as rheumatoid arthritis, psoriatic arthritis, and ankylosing spondylitis. ${ }^{32-34}$

Significant differences were observed among the incurred annual costs in the various JIA subgroups, underlining that JIA is a heterogeneous disease. Costs were highest in patients with seropositive polyarthritis, extended oligoarthritis, or systemic arthritis, while they were lowest in patients having persistent oligoarthritis or enthesitis related arthritis. This is unsurprising, bearing in mind the different long term outcomes of patients with different JIA subtypes ${ }^{9}$ and their different use of medical services. A comparison of the subgroup related costs is restricted owing to lack of data for other patients with juvenile arthritis. Moreover, as cost of illness studies in "adult" arthritis focus on active disease as a rule, with many of them performed at rheumatology disease

Table 5 Annual subgroup related 12 month cost $(€)$ for patients in remission compared with those not in remission

\begin{tabular}{|c|c|c|c|c|c|c|c|c|}
\hline \multirow[b]{2}{*}{ JIA subgroup } & \multicolumn{2}{|c|}{ Mean total cost (SD) (median) } & \multicolumn{2}{|c|}{ Mean healthcare cost (SD) (median) } & \multicolumn{2}{|c|}{$\begin{array}{l}\text { Mean non-healthcare cost } \\
\text { (SD) (median) }\end{array}$} & \multicolumn{2}{|c|}{ Mean indirect costs (SD) (median) } \\
\hline & Remission & No remission & Remission & No remission & Remission & No remission & Remission & No remission \\
\hline $\begin{array}{l}\text { Systemic } \\
\text { arthritis } \\
\text { Oligoarthritis }\end{array}$ & $\begin{array}{l}2971(9024) \\
(65)\end{array}$ & $\begin{array}{l}11086(13139) \\
(4383)\end{array}$ & $\begin{array}{l}930(2392) \\
(65)\end{array}$ & $\begin{array}{l}5707(7840) \\
(2423)\end{array}$ & $\begin{array}{l}36(81) \\
(0)\end{array}$ & $\begin{array}{l}104(183) \\
(24)\end{array}$ & $\begin{array}{l}2005 \text { (8019) } \\
(0)\end{array}$ & $\begin{array}{l}5275(11525) \\
(312)\end{array}$ \\
\hline Persistent & $\begin{array}{l}435(1286) \\
(51)\end{array}$ & $\begin{array}{l}2695 \text { (5929) } \\
(455)\end{array}$ & $\begin{array}{l}312(904) \\
(51)\end{array}$ & $\begin{array}{l}1248(2275) \\
(173)\end{array}$ & $\begin{array}{l}13(42) \\
(0)\end{array}$ & $\begin{array}{l}106(131) \\
(20)\end{array}$ & $\begin{array}{l}111(519) \\
(0)\end{array}$ & $1341(4509)(0)$ \\
\hline Extended & $\begin{array}{l}532(654) \\
(149)\end{array}$ & $\begin{array}{l}11075(18143) \\
(2253)\end{array}$ & $\begin{array}{l}410(589) \\
(149)\end{array}$ & $\begin{array}{l}5561(8966) \\
(1298)\end{array}$ & $\begin{array}{l}123(274) \\
\text { (0) }\end{array}$ & $\begin{array}{l}114(198) \\
(41)\end{array}$ & $\begin{array}{l}0(0) \\
(0)\end{array}$ & $5400(13016)(0)$ \\
\hline \multicolumn{9}{|l|}{ Polyarthritis } \\
\hline $\mathrm{RF}+$ & - & $\begin{array}{l}17180(23957) \\
(6931)\end{array}$ & - & $\begin{array}{l}4517(5070) \\
(3549)\end{array}$ & - & $\begin{array}{l}221(339) \\
(51)\end{array}$ & - & $\begin{array}{l}12442(18698) \\
(3382)\end{array}$ \\
\hline RF- & $\begin{array}{l}373(533) \\
(130)\end{array}$ & $\begin{array}{l}4319(8583) \\
(1223)\end{array}$ & $\begin{array}{l}353(531) \\
(130)\end{array}$ & $\begin{array}{l}1712(3052) \\
(599)\end{array}$ & $\begin{array}{l}20(60) \\
(0)\end{array}$ & $\begin{array}{l}208(314) \\
(84)\end{array}$ & $\begin{array}{l}0(0) \\
(0)\end{array}$ & 2400 (7975) (0) \\
\hline Psoriatic arthritis & $\begin{array}{l}0(0) \\
(0)\end{array}$ & $\begin{array}{l}4248(5574) \\
(4248)\end{array}$ & $0(0)(0)$ & $\begin{array}{l}1704 \text { (1977) } \\
(1705)\end{array}$ & $\begin{array}{l}0(0) \\
(0)\end{array}$ & $\begin{array}{l}51(72) \\
(51)\end{array}$ & $\begin{array}{l}0(0) \\
(0)\end{array}$ & $\begin{array}{l}2492(3524) \\
(2492)\end{array}$ \\
\hline ERA & $\begin{array}{l}165(352) \\
\text { (0) }\end{array}$ & $\begin{array}{l}1485(2892) \\
(116)\end{array}$ & $\begin{array}{l}165(352) \\
(0)\end{array}$ & $\begin{array}{l}1047(2122) \\
(116)\end{array}$ & $\begin{array}{l}0(0) \\
(0)\end{array}$ & $\begin{array}{l}167(288) \\
(0)\end{array}$ & $\begin{array}{l}0(0) \\
(0)\end{array}$ & $\begin{array}{l}270(773) \\
(0)\end{array}$ \\
\hline Other arthritis & $\begin{array}{l}72(143) \\
(0)\end{array}$ & $\begin{array}{l}3503(6450) \\
(850)\end{array}$ & $\begin{array}{l}72(143) \\
(0)\end{array}$ & $\begin{array}{l}3134 \text { (6218) } \\
(719)\end{array}$ & $\begin{array}{l}0(0) \\
(0)\end{array}$ & $\begin{array}{l}49(103) \\
(0)\end{array}$ & $\begin{array}{l}0(0) \\
(0)\end{array}$ & $320(1047)(0)$ \\
\hline All patients & $\begin{array}{l}782(3810) \\
(51)\end{array}$ & $\begin{array}{l}5681(11243) \\
(1170)\end{array}$ & $\begin{array}{l}380(1180) \\
(51)\end{array}$ & $\begin{array}{l}3006(5857) \\
(761)\end{array}$ & $\begin{array}{l}20(78) \\
(0)\end{array}$ & $\begin{array}{l}126(222) \\
(3)\end{array}$ & $\begin{array}{l}382(3271) \\
(0)\end{array}$ & $2549(8226)(0)$ \\
\hline
\end{tabular}

$\mathrm{RF}+$, rheumatic factor seropositive; RF-, rheumatic factor seronegative; ERA, Enthesitis-related arthritis. 
Table 6 Total and indirect costs $(€)$ for the active population $(n=105)$

\begin{tabular}{|c|c|c|c|c|}
\hline \multirow[b]{2}{*}{ JIA subgroup } & \multicolumn{2}{|c|}{ Mean total cost (SD) (median) } & \multicolumn{2}{|c|}{ Mean indirect costs (SD) (median) } \\
\hline & Whole group & Patients not in remission & Whole group & Patients not in remission \\
\hline \multirow{2}{*}{\multicolumn{5}{|c|}{$\begin{array}{l}\text { Oligoarthritis } \\
\text { Ons }\end{array}$}} \\
\hline & & & & \\
\hline Persistent & $348(887)(0)$ & $669(1277)(0)$ & $403(2245)(0)$ & $267(706)(0)$ \\
\hline Extended & $16557(25367)(1300)$ & 18627 (26293) (1777) & $12185(18842)(0)$ & 13708 (18835) (623) \\
\hline $\begin{array}{l}\text { Polyarthritis } \\
\text { RF+ }\end{array}$ & 25744 (26605) (25744) & $25744(26605)(25744)$ & $18663(21611)(18663)$ & $18663(21611)(18663)$ \\
\hline $\mathrm{RF}-$ & $3411(9408)(328)$ & $6458(13126)(432)$ & $2777(9233)(0)$ & $5553(13002)(0)$ \\
\hline Psoriatic arthritis & $2832(4642)(307)$ & $4248(5574)(4248)$ & $1661(2878)(0)$ & $2492(3524)(2492)$ \\
\hline ERA & $1470(3132)(46)$ & 2078 (3663) (133) & $320(833)(0)$ & $469(983)(0)$ \\
\hline Other arthritis & $944(2928)(64)$ & 1560 (3797) (72) & $239(999)(0)$ & $413(1311)(0)$ \\
\hline All patients & $4298(11449)(124)$ & $6906(14066)(655)$ & $2910(9043)(0)$ & $4593(11075)(0)$ \\
\hline
\end{tabular}

centres, $^{32} 3435$ a data comparison is further hampered. Taking this into account, the following relates to JIA patients with an active disease.

In contrast to other musculoskeletal diseases, ${ }^{36}$ the direct cost outweigh the indirect costs in late JIA. This is a result of the nature of the assessed patient cohort, which comprised adolescents and young adults still attending college or university and, therefore, not being available for work. In the active population, however, indirect cost accounted for approximately two thirds of the total cost. This is consistent with estimates in RA, where indirect cost made up 50-75\% of the total cost. ${ }^{36-39}$ Admittedly, work disability and sick leave rates were much lower in late and active JIA, compared with late RA ( $5 \% v 39 \%{ }^{40}$ and $28 \% v 44 \%{ }^{41}$, respectively).

Indirect costs were in turn highest in patients with seropositive polyarthritis and extended oligoarthritis. These were patients who experienced more frequent and more severe functional impairment, which is regarded as a relevant influencing factor on indirect costs. ${ }^{35}$

There were difficulties in estimating indirect costs in this study. On the one hand, indirect costs were possibly underestimated because productivity loss referred only to the active population, and time lost from study by the patients or time lost from work by the patients' families and friends was not considered. Furthermore, a significantly higher proportion of patients were still completing their vocational training compared with the age matched population. It may be that some of these patients deferred their transition into the workforce or were even unable to work. This is supported by the fact that the part time employed incurred a significantly higher cost than the full time employed, which raises the suspicion of part time employment because of JIA. On the other hand, there may have been an overestimation of indirect cost as a result of using the human capital approach in a country with an unemployment rate of $12 \%$ among young adults. ${ }^{29}$ By applying the friction cost method, the indirect cost would be only a tenth of that estimated by the human capital method, reducing the total cost to $€ 1100$ per patient in the active population.

The direct cost analysis revealed that in accordance with the majority of studies in $\mathrm{RA}^{34}{ }^{37-39}$ inpatient care was the main source of expenditure in JIA. Even though only $12 \%$ of patients required inpatient care, it was responsible for more than half the direct costs. Patients with active disease under specialised care incurred significantly higher direct cost than those not receiving rheumatological care, as would be expected. However, these patients also incurred higher indirect costs because they were the more severe cases. In view of the long term morbidity and mortality in JIA, ${ }^{11-13} 42$ these data should not lead to the conclusion that specialised care simply increases cost of illness. The consequences of absence of specialised care in late, still active JIA should be addressed in further follow up studies.

Self report questionnaires are an attractive, cost effective approach to assess the intangible cost for an individual patient. ${ }^{43}$ Quality of life, functional status, and depression measures are particularly used to evaluate the "price" paid by the patient. In this study, approximately one in 10 patients showed substantial impairment of quality of life and functioning or felt considerably burdened by their illness. These were the patients who incurred the major share of the cost. Compared with other studies evaluating the impact of a chronic rheumatic disease, this is a rather low proportion. ${ }^{44} 45$ This could be explained by the fact that many patients, growing up with the disease, have adapted to their limitations, or that the chosen measures to assess the patients' health were not sensitive enough to disclose all the problems with which adolescents and young adults with JIA have to cope. The latter assumption is supported by the fact that twice as many patients stated the need of support in daily life when asked in general, compared with when asked using the HAQ.

As with any study, the results have to interpreted in the light of the study's limitations. Cost estimation relied on self reported data where recall bias cannot be ruled out. This especially applies to the reported number of work days lost over the preceding 12 months, which is a very long recall period. "Standard" assigned cost per day, per visit, or per prescription based upon publicly available figures were used in this analysis, while the actual cost may vary from those considered. Further, the number of patients within some subgroups was relatively small. Otherwise, this study was incidence and population based and the obtained data can therefore be regarded as representative. An overestimation of cost due to patient selection can definitely be excluded.

This study gives an estimate of 12 month cost in late JIA, being only a fraction of the life long cost of illness. Further research should involve patients with recent onset of JIA and collect detailed cost data that can be used to assess the efficacy and cost effectiveness of different treatment strategies in JIA.

\section{ACKNOWLEDGEMENTS}

This study was supported by a grant (no. FB2 43346-8/13) from the Federal Ministry of Education, Science, Research and Technology.

\section{Authors' affiliations}

K Minden, M Niewerth, J Listing, A Zink, German Rheumatism Research Centre Berlin, Epidemiology Unit, Berlin, Germany

K Minden, T Biedermann, M Schöntube, Helios Clinics, 2nd Children's Hospital Berlin-Buch, Rheumatology Unit, Berlin, Germany 


\section{REFERENCES}

1 Cooper NJ. Economic burden of rheumatoid arthritis: a systematic review. Rheumatology (Oxford) 2000;39:28-33.

2 Wong JB, Ramey DR, Singh G. Long-term morbidity, mortality, and economics of rheumatoid arthritis. Arthritis Rheum 2001;44:2746-9.

3 Kobelt G, Jonsson L, Lindgren P, Young A, Eberhardt K. Modeling the progression of rheumatoid arthritis: a two-country model to estimate costs and consequences of rheumatoid arthritis. Arthritis Rheum 2002;46:2310-19.

4 Fautrel B, Guillemin F. Cost of illness studies in rheumatic diseases. Curr Opin Rheumatol 2002;14:121-26.

5 Merkesdal S, Ruof J, Mittendorf T, Mau W, Zeidler H. Health economics research in the area of chronic polyarthritis. Z Rheumatol 2002;61:21-9.

6 Reginster JY. The prevalence and burden of arthritis. Rheumatology (Oxford) 2002;41(Suppl 1):3-6.

7 Allaire SH, DeNardo BS, Szer IS, Meenan RF, Schaller JG. The economic impacts of juvenile rheumatoid arthritis. J Rheumatol 1992;19:952-5.

8 Cummins C, Connock M, Fry-Smith A, Burls A. A systematic review of effectiveness and economic evaluation of new drug treatments for juvenile idiopathic arthritis: Etanercept. Health Technol Assess 2002;6:1-43.

9 Minden K, Niewerth M, Listing J, et al. Long-term outcome in patients with juvenile idiopathic arthritis. Arthritis Rheum 2002;46:2392-401

10 Flatø B, Lien G, Smerdal A, et al. Prognostic factors in juvenile rheumatoid arthritis: A case-control study revealing early predictors and outcome after 14.9 years. J Rheumatol 2003;30:386-93.

11 Peterson LS, Mason T, Nelson AM, O'Fallon WM, Gabriel SE. Psychosocia outcomes and health status of adults who have had juvenile rheumatoid arthritis. Arthritis Rheum 1997; 12:2235-40.

12 Zak M, Pedersen FK. Juvenile chronic arthritis into adulthood: a long-term followup study. Rheumatol 2000;38:198-204

13 Packham JC, Hall MA. Long-term follow-up of 246 adults with juvenile idiopathic arthritis: functional outcome. Rheumatology (Oxford) 2002;41:1428-35.

14 Packham JC, Hall MA. Long-term follow-up of 246 adults with juvenile idiopathic arthritis: education and employment. Rheumatology (Oxford) 2002:41:1436-9.

15 Petty RE, Southwood TR, Baum J, Bhettay E, Glass DN, Manners P, et al. Revision of the proposed classification criteria for idiopathic arthritides of childhood: Durban 1997. J Rheumatol 1998;25:1991-4.

16 Steinbrocker O, Traeger CH, Battermann RC. Therapeutic criteria in rheumatoid arthritis. J Am Med Ass 1949;140:659-63.

17 Pinals RS, Masi AT, Larsen RA. Preliminary criteria for clinical remission in rheumatoid arthritis. Arthritis Rheum 1981;24:1308-15.

18 Lautenschläger J, Mau W, Kohlmann T, et al. Comparative evaluation of a German Version of the Health Assessment Questionnaire (HAQ) and the Hanover Functional Status Questionnaire (FFbH). Z Rheumatol 1997;56:144-55

19 Westhoff G, Erhart M. Validation of the German version of a disease-specific quality of life instrument for patients with rheumatoid arthritis (RAQoL). Z Rheumatol 2000;59(Suppl 3):S61

20 Hautzinger $M$, Bailer M. ADS, general depression scale. Beltz Test GmbH, Weinheim, 1993

21 Merkesdal S, Ruof J, Schoffski O, et al. Direct cost-savings after a selfmanagement program in patients with RA. Arthritis Rheum 1999:42(Suppl):S387.

22 Statistics of the Federal Association of panel doctors. Data on health care provision by panel doctors in the Federal Republic of Germany of the year 1999. http://www.kbv.de/publikationen/grunddaten.htm.

23 German Association for physiotherapy-Federation of physiotherapists Health insurances AOK/BKK/IKK/VdAK, 2001. httpwww.kv-thueringen.de/ site/pub/rundschreiben_2000/RS_05_anlage_5.pdf
24 Rote Liste ${ }^{\circledR}\left(\right.$ Red List $\left.^{\circledR}\right)$. German Pharmaceutical index 1999. In: Rote Liste Service GmbH, Aulendorf Frankfurt/Main: ECV Editio Cantor Verlag GmbH. 25 (Price guidelines for statutory health insurance). Berlin: AOK.

26 Federal Statistical Office. Issue 12, Series 6.3, 1999. http www.statistikbund.de/presse.

27 Catalogue of lump compensation. The association of staffers health insurance companies. http://www.vdak.de.

28 Rehabilitation Statistics of the Federation of German Pension Insurance Institutes of the year 1999. Frankfurt/Main, VDR.

29 Statistical book of the year 1999. Wiesbaden: Federal Statistical Office, 1999.

30 GAUSS $^{T M}$, advanced mathematical and statistical system. http:// www.aptech.com.

31 Brouwer WB, van Exel NJ, Koopmanschap MA, Rutten FF. Productivity costs before and after absence from work: as important as common? Health Policy 2002;61:173-87.

32 Boonen A, van der Heide D, Landewé R, et al. Work status and productivity costs due to ankylosing spondylitis: comparison of three European countries. Ann Rheum Dis 2002;61:429-37.

33 Cooper NJ, Mugford M, Symmons DPM, Barrett EM, Scott DGI. Total costs and predictors of costs in individuals with early inflammatory polyarthritis: a community-based prospective study. Rheumatology 2002;41:767-74.

34 Huscher D, Thiele K, Merkesdal S, Zeidler H, Zink A, German Collaborative Arthritis Centres. Comparison of the annual direct and indirect costs in arthritis, ankylosing spondylitis and psoriatic arthritis. Arthritis Rheum 2002;46(Suppl):S93.

35 Leardini G, Salaffi F, Montanelli R, Gerzeli S, Canesi B. A multicenter cost-ofillness study on rheumatoid arthritis in Italy. Clin Exp Rheumatol 2002;20:505-15.

36 Jonsson D, Husberg M. Socioeconomic costs of rheumatic diseases. Implications for technology assessment. Int J Technol Assess Health Care 2000;16:1193-2000.

37 Pugner KM, Scott DI, Holmes JW, Hieke K. The costs of rheumatoid arthritis: an international long-term view. Semin Arthritis Rheum 2000;29:305-20.

38 Cooper NJ, Mugford M, Scott DG, Barrett EM, Symmons DP. Secondary health service care and second line drug costs of early inflammatory polyarthritis in Norfolk, UK. J Rheumatol 2000;27:2115-22.

39 Birnbaum HG, Barton M, Greenberg PA, et al. Direct and indirect costs of rheumatoid arthritis to an employer. J Occup Environ Med 2000;29:305-20.

40 Barrett EM, Scott DGI, Wiles NJ, Symmons DPM. The impact of rheumatoid arthritis on employment status in the early years of disease: a UK communitybased study. Rheumatology 2000;39:1403-9.

41 Zink A, Mau W, Schneider M. Epidemiological and public health aspects of inflammatory rheumatic systemic diseases. Internist 2001;42:211-16, 219-22

42 Thomas E, Symmons DP, Brewster DH, Black RJ, Macfarlane GJ. National study of cause-specific mortality in rheumatoid arthritis, juvenile chronic arthritis, and other rheumatic conditions: a 20 year followup study. J Rheumatol 2003:30:958-65.

43 Pincus T, Callahan LF, Brooks RH, Fuchs HA, Olsen NJ, Kaye JJ. Self-report questionnaire scores in rheumatoid arthritis compared with traditional physical, radiographic, and laboratory measures. Ann Intern Med 1989:110:259-66

44 Ward MM. Functional disability predicts total costs in patients with ankylosing spondylitis. Arthritis Rheum 2002;46:223-31

45 Lapsley HM, March LM, Tribe KL, Cross MJ, Courtenay BG, Brooks PM, Arthritis Cost and Outcome Project Group. Living with rheumatoid arthritis: expenditures, health status, and social impact on patients. Ann Rheum Dis 2002;61:818-21 